\title{
Time to First Optimal Glycemic Control and its Predictors Among Type 1 Diabetic Children<15 Years in Bahir Dar City Public Referral Hospitals, North West Ethiopia: A Retrospective Follow Up Study
}

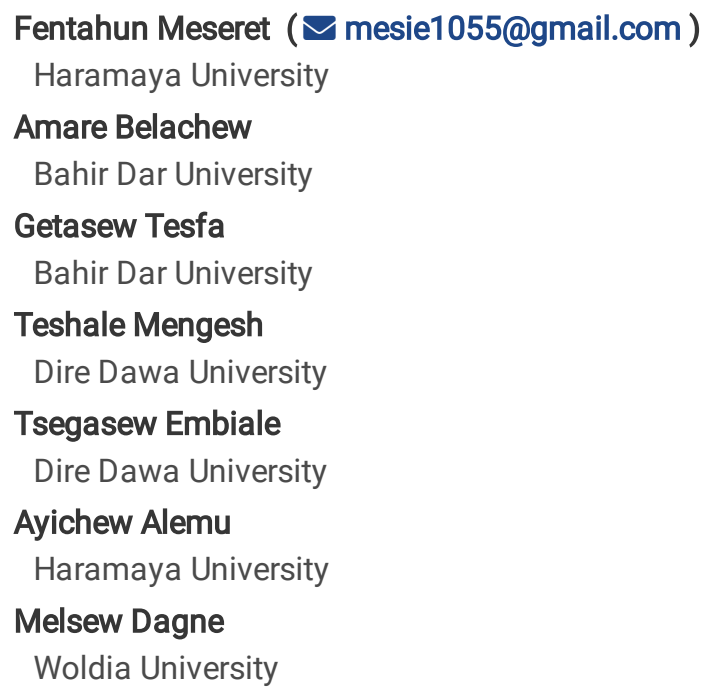

Research Article

Keywords: type 1 diabetes mellitus, First optimal glycemic control, Time, children, Ethiopia

Posted Date: November 3rd, 2021

DOI: https://doi.org/10.21203/rs.3.rs-982922/v1

License: (c) (1) This work is licensed under a Creative Commons Attribution 4.0 International License. Read Full License 


\section{Abstract}

Background: Recognizing the level of glycemic control of a client is an important predictor of the development of complication and risk of death from diabetes. However, the other most important predictor which is the time that the patient stayed in that poor glycemic level before reaching optimal glycemic control has not been studied so far.

Objective: The aim of this study was to estimate time to first optimal glycemic control and identify predictors among type 1 diabetic children $<15$ years in Bahir Dar city public referral hospitals, Northwest, Ethiopia, 2021

Methods: Retrospective cohort study was conducted at Bahir Dar city public referral hospitals among randomly selected sample of 385 patients with type 1 diabetes who were on follow up from January1, 2016 to February30, 2021.Data were collected by using data abstraction tool and then entered into Epi-data version 4.2 and exported into STATA 14.0 statistical software. Descriptive statistics, Kaplan Meier plots and median survival times, Log-rank test and Cox-proportional hazard regression were used for analysis. After performing Cox-proportional hazard regression, model goodness-of-fit and assumptions were checked. Finally, association between independent variables and time to first optimal glycemic control in months were assessed using multivariable Cox Proportional Hazard model and Variables with $p$-value $<0.05$ were considered as statistically significant.

Result: Median survival time to first optimal glycemic control among type 1 diabetic client was 8 months (95\%Cl: $6.9-8.9)$.First optimal glycemic achievement rate was 8.2(95\% Cl: 7.2-9.2) per 100 person/month observation. Factors that affect time to first optimal glycemic control were age $(A H R=0.32 ; 95 \% \mathrm{Cl}=0.19-0.55)$, weight $(A H R=0.96 ; 95 \% \mathrm{Cl}=0.94-0.99)$, primary care giver $(A H R=2.09 ; 95 \% \mathrm{Cl}=1.39-3.13)$, insulin dose $(A H R=1.05 ; 95 \% \mathrm{Cl}=1.03-1.08)$, duration of diabetes (AHR=0.64;95\%Cl=0.44-0.94), adherence (AHR=9.72;95\% Cl=6.0915.51), carbohydrate counting( $\mathrm{AHR}=2.43 ; 95 \% \mathrm{Cl}=1.12-5.26)$, and comorbidity $(\mathrm{AHR}=0.72 ; 95 \% \mathrm{Cl}=0.53-0.98)$.

Conclusion and Recommendation: The median survival time to first optimal glycemic control in this study was long. Age, weight, primary care giver, insulin dose, duration of diabetes, adherence, and carbohydrate counting including history of comorbidity were determinant factors. Therefore, clinicians should advice weight reduction, increase the dose of insulin during initial treatment, counsel their parents about adherence of insulin drug and auditing their children diet as prescription helps to reduce the length of glycemic control.

\section{Introduction}

Diabetes mellitus(DM) is a serious, chronic and progressive disease that occurs either when the pancreas does not produce enough insulin or the body can not properly use the insulin it produces(1). There are three classification of diabetes mellitus commonly accepted by different scholars $(1,2)$. These are: type one diabetes mellitus (T1DM), type two diabetes mellitus( T2DM) and gestational diabetes(3).According to American diabetic association(ADA) type one is the commonest type in pediatrics age categories(2).

Type 1 diabetes also known as insulin dependent, juvenile or child hood onset DM which is characterized by deficient insulin production in the body(1). It encompasses a group of metabolic disease causing in hyperglycemia(2). Juvenile diabetes is currently not preventable but we can control and prevent its complication. Otherwise, uncontrolled diabetes over time may lead to a serious damage to the heart, blood vessels, eyes, kidneys and nerves(1-5) .

A patient indicating any of the following can diagnosed as having diabetes based on ADA and international society of pediatrics and adolescent diabetes(ISPAD): fasting blood glucose $(\mathrm{FBG}) \geq 126 \mathrm{mg} / \mathrm{dL}(11.1 \mathrm{mmol} / \mathrm{L})$, poly symptoms of diabetes plus random blood sugar $\geq 200 \mathrm{mg} /(7 \mathrm{mmol} / \mathrm{L})$ or 2 hour plasma glucose during glucose tolerance test. $\geq 200 \mathrm{mg} /(7 \mathrm{mmol} / \mathrm{L})$ and glycosylated/glycated $(\mathrm{Hb} \mathrm{A1}) \geq 6.5 \% .(2,6)$.

Glycemic control is a level of glucose in diabetic clients(1);Glycemic control followed by the diagnosis was reflected by optimal and poor metabolic control as mean $\mathrm{HbA} 1 \mathrm{c}<7.5 \%$ and $>7.5 \%$ respectively and /or average FBG level between $80-150 \mathrm{mg} / \mathrm{dl}$ and either $<80$ or $>150$ $\mathrm{mg} / \mathrm{dl}$ respectively $(6-8,80)$ and $\mathrm{HbA} 1 \mathrm{c}$ can be calculated from the following formula, if HBA1c is not consistently available for some of the clients; estimated average glucose level in $(\mathrm{mg} / \mathrm{dl})=28.7^{*} \mathrm{HbA} 1 \mathrm{c}-46.7(8)$.

Diabetes mellitus pandemic have become one of the largest global health emergencies among non-communicable disease in this century(3). In many countries, over 500000 children $<15$ years old are diagnosed with T1DM(4, 6-8)with an average incidence of 3-4\% per year worldwide $(6,7)$. This increment is also noted more alarmingly in developing countries $(9,10-14)$. 
Although there are a lots of advanced management of T1DM,more than $70 \%$ of them were unable to maintain their glycaemia(10, 11). More over noncompliance rate escalating $50 \%$ that highlights the need for focusing on timely optimal glycemic control(10). Many children had also suffered from T1DM which is associated with high morbidity, mortality rate and most of the time the poor has been highly affecting by this disease $(9,15,16)$. Both In developed and developing nations the prognosis of children with T1DM is poor (14). As a result, optimal glycemic control were oscillating from $2.6-39.1 \%(11,15,17)$. Many are not detected and those diagnosed have dramatically reduced their life expectancy by one year,(17-19). Poor glycemic control was much higher among type one patients(82.9\%) as compared with type two diabetics(57.7\%)(14, 20, 21).

A varieties of factors that predict glucose control in children with T1DM have documented $(7,18-22)$. High proportion of patients with uncontrolled glycemic level were due to sociodemographic factors, concomitant disease, personal and other clinical factors $(16,17,23)$; health care system with limited resources, lack of trained health personnel and in ability of the patient or family to use and afford treatment expenditures $(10,24)$.

Uncontrolled glycemic situation results complication which can hurt many parts of the body including growth failure later in time $(3,22-$ 24). As a result, both acute and chronic complications were reported in different studies(24).Adverse effects like lipodystrophy is one of the clinical complication which may occur related to insulin injection and leads to insulin absorption problems, which ultimately can hinder first optimal glycemic control $(25,26)$. The most common complication prior in three months were hypoglycemia(21-42\%) followed by $31.5 \%-39 \%$ of diabetic keto acidosis(DKA), $10.5 \%-32.9 \%$ of nephropathy, $13.6 \%$ of neuropathy, $10.5 \%$ of convulsion, $10.3 \%$ of retinopathy (27-29). Sustained abnormal blood sugar fluctuation for periods of greater than two months can also contribute to high burden of the disease, hospitalization and negative consequences of disease out comes(30, 32).

Similarly, study in Ethiopia highlights the difficulty of achieving glycemic control early in time. As a result, early occurrence of both retinopathy and maculopathy among diabetic children were reported(13). Another study In Ethiopia specifically in Gojjam, also indicates $58.5 \%$ DKA among 354 T1DM children with the incidence rate of 2.27/100 children/month of observation.(31).

However, strict glycemic control minimizes the incidence and progression of such possible complication(14-17).The Diabetes Control and Complication Trial (DCCT) and the follow-up study Epidemiology of Diabetes Interventions and Complications (EDIC) shows that, good glycemic control with in short duration delays the development of both acute and chronic complication in T1DM patients by 35$76 \%$ (9).Novel treatment are emerging to manage T1DM with the ultimate goal being to achieve glycemic control, limit weight gain, reduce comorbidities and improve quality of life(7).T1DM treatment is based on frequent monitoring of blood glucose and administration of insulin, in line with their meal and exercise(33-35).It was recommended that T1DM children should check their blood glucose at least four times a day(6).And which expected to bring $26.2 \%$ satisfactory glycemic control level $(7,35)$.People with diabetes can live longer and have a healthy life if their diabetes is become aware of early and well-managed by multidisciplinary approach with the allocation of accessible resources $(10,36,37)$. Being updated about the recent diabetes care can also help in improving first glycemic control $(15,38)$.

In Ethiopia a little studies were conducted to recognize level of glycemic control among type one diabetic children(16). However, the other most important parameter, which is the time, in which, the patient stayed on that poor glycemic level before reaching optimal glycemic control has not studied so far. If efforts are not made to recognize the contributing factors for optimal glycemic control with possible time frame, the number of children affected will preserve growing and this in turn lead to an emotional and economical burden on both the clients and the families at large(6).And it will also disturb the sustainability of our health care system which is still over burdened with communicable diseases.

Therefore, this study was aimed to estimate time to first optimal glycemic control among type 1 diabetic children in Bahir Dar city public referral hospitals, Northwest, Ethiopia.

\section{Methods And Materials Study area and period}

The study was conducted in Bahir Dar city; located $565 \mathrm{Km}$ far from Addis Ababa, the capital city of Ethiopia, at Amhara national regional state, North West Ethiopia. In Bahir Dar city there are two public referral hospitals, one primary hospitals, ten health center and four private hospitals. And this study was conducted in the two public referral hospitals, namely: Felege Hiwot comprehensive specialized referral hospital (FHCSH) and Tibebe Ghion specialized teaching hospital (TGSTH). Each of this hospital can be expected to 
serve for more than 10 million populations coming from Bahir Dar city, west Gojjam zone, east Gojam zone, awi zone, north and south wollo zones, south\& north Gondar zones, partial part of Benshangul Gumuz and Oromia region. FHCSH has currently a total of 1431 man power in each discipline with 500 formal beds, 11 wards, 39 clinical and non-clinical departments /service unit / providing Diagnostic, curative, Rehabilitation and preventive service at outpatient \&inpatient based. Similarly TGSTH is a teaching hospital under Bahir Dar University College of medicine and health sciences that has 459 bed capacity and with around 14 outpatient departments.

Apart from other services both referral hospitals provide diabetic treatment services by nurse practitioners, pediatrics residents and pediatricians.

The study period address from1stJanuary, 2016 to February 30 /2021.

\section{Study design}

An institution based retrospective follow up study was employed.

\section{Source population}

The source population were all type 1 diabetes mellitus children< 15 years old who had follow up at diabetes clinic of the two referral hospitals.

\section{Study population}

The study population were all type 1 diabetes mellitus children $<15$ years old who were on follow up during the study period.

\section{Study unit}

All type one diabetic children's chart that were selected randomly for investigation.

\section{Inclusion criteria}

Children age less than 15 years old and diagnosed with T1DM with regular follow up and had at least one HbA1c and/or a three month consecutive measurements of fasting blood sugar (FBS) with clear date of diagnosis between January 1/2016 to February 30/2021 were included.

\section{Exclusion criteria}

Children's medical record/chart with incomplete information (such as $\mathrm{HbA1c/average} \mathrm{FBG} \mathrm{and} \mathrm{other} \mathrm{relevant} \mathrm{predictors} \mathrm{like} \mathrm{age} \mathrm{with}$ date of diagnosis, sex, treatment modality, frequency of follow up visit and last visit health condition of the children), those having less than 3 month follow up during the study period and those cases transferred in with unclear date of diagnosis from other institution were excluded from the study.

\section{Sample size determination}

Sample size was determined by double proportion formula after taking of predictors associated to optimal glycemic control from previous study conducted by retrospective cohort design (50)with the help of epi info version 7 by considering the following statistical assumptions: $95 \%$ Confidence Interval (Cl), power $80 \%$,percent of outcome in unexposed group $8.93 \%$,risk ratio 0.253 , marginal error $5 \%$ (50). The calculated total sample size is 378 , then by adding $10 \%$ for data incompleteness from the client chart, the final sample size became 416 .

\section{Sampling technique and procedure}


The study participants were selected from the registration book. The medical records of children who were on follow up with type one diabetes mellitus from January 2016 to February 2021 were selected. A total of 721 children were recorded from the registration book of the two referral hospitals (sampling frame). Of which 416 cards were sampled using a simple random sampling technique by a computer generating method. Finally, cards that fulfilled the criteria were reviewed.

\section{Dependent variables}

\section{Time to first optimal glycemic control \\ Independent variables}

Socio demographic (age, gender, Residence); Institutional related variable (frequency of clinic visit); Diabetic related variables (duration of diabetes, diabetes related complication.); Comorbidities (preceding infections and other pathology) and treatment related variables (insulin therapy and adherence, noncompliance and other self-monitoring practice)

Age of the participants, frequency of glycemic control, body mass index and duration of diabetes were categorized in to groups in order to alien with the other literatures $(36,40,50)$

\section{Operational definitions}

Optimal glycemic control: Optimal glycemic control is defined as the three consecutive month $\mathrm{HbA} 1 \mathrm{c}<7.5 \%$ and/or average FBG of $80-$ $150 \mathrm{mg} / \mathrm{dl}$ with more or less stringent glycemic goals for individual clients based on age/life expectancy, comorbid condition, advanced complication, hypoglycemia unawareness and individual patient considerations $(6-8,80)$.

Event: Achieving first optimal glycemic control during the study period

Survival time: The time starting from date of diagnosis to first optimal glycemic control was determined for each participant

Censoring: Patients died, lost to follow up, transferee out, and complete the follow up period without achieving optimal glycemic control

Time to event: Time between diagnosis up to achieving first optimal glycemic control or censoring with measure of interest in month

Carbohydrate counting: Practicing healthy diet at home by non-refined carbohydrate utilization and eating consistent amount of food regularly with application of food pyramid as a meal planning tool to optimize blood sugar level (35).

\section{Data collection procedure}

The data were collected from patients chart that visit Felege Hiwot comprehensive specialized referral hospital and Tibebe Ghion specialized teaching hospital. Data that were relevant to measure the association between times to first optimal glycemic control among diabetic children were collected by two BSc nurses supervised by one senior nurse having second degree in public health.

Patient records were retrieved using their medical registration number identified in the total DM case load in the logbook of registration follow up form. Then medical registration number (MRN) of all diabetic pediatric patient were sorted. After that, the sample selection mechanism was simple random sampling technique, in which each of the patients had equal chance of being selected to be part of study.

A structured data extraction tool adapted by considering study variables such as socio demographic, personal and clinical predictors from patients' charts.

\section{Data quality assurance}

Training was given for data collectors and supervisors about the objective and process of data collection by the principal investigator. Pretest was done on $5 \%$ of sample size. Then pretested data abstraction tool/check list that comprises of questions to measure the relevant variables were used to collect the necessary data from the patient medical chart by those trained data collectors. Data quality 
was also assured by designing proper data abstraction tool and through continuous supervision. All collected data were checked for completeness and clarity.

\section{Data processing and statistical analysis}

The collected data was coded, enter, cleaned and stored into Epi-data version 3.1 and exported into STATA 14.0 statistical software for analysis. Descriptive statistics were presented with frequency tables, Kaplan Meier (KM) plots and median survival times. Months are used as a time scale to calculate time to first optimal glycemic control. The outcome of each participant was dichotomized in to censured or event (first optimal glycemic control)

Kaplan-Meier technique was used to measure survival experience of diverse groups of patients by using survival curves. Log-rank test was used to assess significant difference among survival distributions of groups for equality. After performing the Cox-proportional hazard regression, model goodness-of-fit was checked by Cox Snell residuals \& assumptions was checked by using Shenfield residual test and graphically by using log minus log function survival curves.

Bivariable analysis was performed to calculate crud hazard ratio (CHR) and to screen out potentially significant independent variables at $p$ value $<0.25$ level of significance.

Association between the significant independent variables and the time to first optimal glycemic control was assessed using multivariable Cox Proportional Hazard (PH) model.

Adjusted hazard ratio (AHR) and 95\% Cl for HR were used to test significance and interpretation of results.

Variables with $p$-value $<0.05$ were considered as statistically associated with the time to first optimal glycemic control in months.

\section{Ethical considerations}

Ethical clearance was obtained from the institutional review board (IRB) of Bahir Dar University (IRB number 01-008). Written supportive letter was taken from pediatrics department of the hospitals on behalf of the patients. This study had no any danger or negative consequences for the study participants. Medical record numbers were used for the data collection and personal identifiers of the client were not used in this research report. Access to collected information was limited to the principal investigator and confidentiality had preserved throughout the time.

\section{Results}

\section{Socio demographic characteristicswith censuring and event status}

Four hundred sixteen (416) medical records were reviewed; off which, thirty one $(7.5 \%)$ cases were excluded from the study due to pertinent data being missing. As a result, 385 clients were included in the study which is $92.5 \%$ in response rate.

Mean age of the study participant was $8.2 \pm 4.7$ years with 2.4 years mean duration of diabetes.

More than half of the patients were male (53\%) and proportion of first optimal glycemic achievement among male is $(72 \%)$ which is almost proximal to female (71.3\%).

Majority of the patients (64.7\%) were from rural area. However, the Proportion of patients who achieved first optimal glycemic control among rural is (68.7\%) which is lower than clients from urban area residents $(77.2 \%)$.

Those clients having $>4$ clinical visit for the last year of their follow up had higher proportional glycemic control (82.3\%) than clients having clinical visit $<=4(663 \%)$. (Table 2$)$.

\section{Median survival time to first optimal glycemic control}

The estimated median survival time to achieve first glycemic control was 8 months with inter quartile range of (6.9-8.9). 
The median survival time to first optimal glycemic control among type one diabetic children were varied by various categories of predictors. For example, the median survival time to achieve first optimal glycemic control among under 5 children was 6.8 where as in above $5-10$ and $>10-14$ years was $8,8.5$ respectively. (Table 5 ).

\section{Incidence rate of optimal glycemic achievement rate}

From 385 study participants, $276(71.7 \%)$ of the clients have achieved glycemic control with mean value of FBG\&HA1c $(112 \pm 3 \mathrm{mg} / \mathrm{dl}$, $5.6 \%)$ respectively; whereas $109(28.3 \%)$ were censored. The lowest and the highest length of follow up were 2.9 and 36.4 months respectively, and the total person-time risk was 3373 months.

The overall first optimal glycemic control rate was 8.2(95\%Cl: 7.2-9.7) per 100 person/month observation. Optimal glycemic achievement rate among male and female children with type 1 diabetes was $7.9(95 \% \mathrm{Cl}: 6.7-9.3)$ per 100 person/month and $8.4(95 \% \mathrm{Cl}$ : 7.1-10.0) per 100 person/month observation respectively which is nearly comparable in both sex.

\section{Diabetes related variableswith censuring and event status}

Concerning complication, $83.4 \%$ of the patients had history of one or more diabetes related complication .Majority of the clients had diabetic keto acidosis (DKA) (81\%) including the episodes at the time of diagnosis followed by hypoglycemia (19.7\%), other complication (4.9\%) and chronic complication $(0.8 \%)$. The proportion of patients who achieved optimal glycemic control is relatively higher among those with no history of diabetes related complication (76.6\%) as compared to those with history of complication (70.7\%).Mixed insulin (lent \&regular) drugs had given for the majority of the patients (62.9\%) during the initiation of treatment as compared to other regimens like NPH with regular and NPH alone $(20 \%, 17.1 \%)$ respectively. (Table 3$)$.

\section{Comorbidity related variableswith censuring and event status}

In regard to comorbidity, $69.6 \%$ of the patients had history of comorbid illness and only $30.4 \%$ of them didn't have recognized history of comorbid illness. Majority of the clients had malnutrition (38.7\%) followed by pneumonia (16.1\%), urinary tract infection (13.8\%), acute gastro enteritis (10.1\%), fungal infection ( $7 \%$ ) and upper respiratory tract infection $(6.5 \%)$. Nearly half (48\%) of the patients had more than one comorbid illness. The proportion of clients who achieved first optimal glycemic control is higher among those with no history of comorbid illness (74.4\%) than those with one or more comorbid illness (70.5\%). (Table 4).

\section{Survival estimates for time to first optimal glycemic control}

The survival status of children with type 1 diabetes was estimated by the Kaplan-Meier survival curve.

The curve tends to decrease rapidly with in the first one year indicating that most children achieved first optimal glycemic control within this time (Figure 2).

The survival estimates of clients were varied in relation to different predictors. (Figure 3).

\section{Comparison of survival experience}

The long rank test was used to assess differences in equality of survival distribution among diverse groups. The median survival time to achieve first optimal glycemic control among clients in the age groups of $<=5$ years showed shorter median time to achieve first optimal glycemic control (6.8 months) as compared with patients whose age group between 6-10 years (8months) and 11-14 years (8.5 months).and the survival time was significantly different among the age groups $\left(X^{2}(2)\right)=6.05$, P-value $\left.=0.0486\right)$. whereas, the median survival time to achieve first optimal glycemic control among male participant showed relatively longer time ( 8.5 months) than females (7.2 months).But the long rank test was not statistically significant $\left.\left(X^{2}(1)\right)=0.92, p-v a l u e=0.3378\right)$. (Table 5).

Regarding adherence, those clients who adhere to the management had shorter duration of time (5.7 months) to achieve first optimal glycemic control than those who didn't adhere towards the management of the disease(14.9 months). The long rank test was 
statistically significant $\left(X^{2}(1)\right)=131.75$, P-value $\left.<0.0001\right)$. The Kaplan Meier survival function showed that, clients with adherence have satisfactory survival experience by achieving their glycemic targets early in time. The figure also showed that, clients direct chance of achieving first optimal glycemic control increases for both group as the duration of treatment increases. (Figure 4).

Those patients having comorbid illness appears to extend time to first optimal glycemic control. The median survival time to achieve optimal glycemic control was shorter among patients with no history comorbid illness ( 6.3 months) than patients who had comorbid illness (8.9 months) with statistical significant difference among the group $\left(X^{2}(1)\right)=10.85$, P-value $\left.=0.0010\right)$. (Table 5).

However, no statistically significance difference were shown for sex, residence, family history of diabetes militias, number of clinic visit ,DKA as presentation and being malnourished in determining time to first optimal glycemic control. (Table 5 \& Table 6).

\section{Results of multivariable cox proportional hazard model}

Goodness of fit checked by cox Snell residuals by plotting cox Snell residual against the cumulative hazard function. As a residuals follow unit of exponential distribution or a linear line through the origin with a unit gradient, which indicates a well fitted model to the observed data point and expected value. (Figure 5).

Proportional assumption of cox proportional hazard model was tested by using Schoen field residual test and graphically by using log minus log function on Stata version 14.2 (Table 6\& Fig 6). The survival curve looks like parallel throughout the study time; which shows equitable fitting to the proportional hazard assumption.(Figure 6).

The independent variables such as age client educational status, primary care giver, dose of insulin at initiating of treatment, duration of diabetes, first insulin regimen, current insulin regimen, frequency of glycemic control, carbohydrate count, exercise, noncompliance, adherence, diabetes related acute complication, having history of comorbidity were significantly associated with time to first optimal glycemic control at the point less than 0.25 level of significance from bivariable analysis. However, only age, duration of DM, dose of insulin at initiating of treatment, weight, primary care giver, adherence to DM care, carbohydrate counting and history of comorbidity were found to be significantly associated with time to first optimal glycemic control in the multivariable cox regression hazard model less than $5 \%$ level of significance.

The presence of interaction among independent variables were checked by multicollinearity test but there was no significant interaction as it was confirmed by the value of variance inflation factor (VIF) which is less than ten..

Consequently, after adjusting other predictor, the hazard of achieving optimal glycemic control among the age groups $>10-14$ years were lower by $67.6 \%$ as compared with the age groups of the client $<=5$ years $(\mathrm{AHR}=0.324,95 \% \mathrm{Cl}=0.192-0.546)$.

Likewise, the hazard of achieving optimal glycemic control among clients with history of comorbid illness was lower by $24.3 \%$ compared to clients with no history of comorbid illness ( $\mathrm{AHR}=0.722,95 \% \mathrm{Cl}=0.530-0.981$ ).this means, the time needed to reach optimal glycemic control among clients with history of comorbid illness was significantly longer compared with clients with no history of comorbid illness.

However, the rate of achieving first optimal glycemic control among clients who adhered to diabetic care had 9.7 times increment than clients who didn't adhered to diabetic management (AHR=9.723, 95\%Cl=6.094-15.513). (Table 6).

\section{Discussion}

The aim of this study was to identify predictors of time to optimal glycemic control in Ethiopia. The estimated median survival time to achieve first glycemic control was 8 months with inter quartile range of (6.9-8.9). The finding in this study is in line with another study conducted among type 1 diabetic children in united states (38) but a little bit shorter than previous study conducted in Ethiopia(9.5months) (3).This could be due to differences in age pattern, type of diabetes and comorbidity among study participants(28, $31,47,49,50,55,57-60)$.

The overall first optimal glycemic control rate was 8.2(95\%Cl: 7.2-9.7) per 100 person/month observation. The finding related to overall incidence rate to achieve glycemic target in this study is less than other studies conducted in Kenya (28\%),Jordan (20.9\%), Saudi Arabia $(39.1 \%)$, and California( $33 \%)(39,40,50,51)$ but greater than a study done in Tanzania(2.6\%)(26). This discrepancy can be due to differences in population characteristics, sample size, study methodology and overall health care system including resource allocation $(10,16,17,23,24,52)$. 
In regard to predictors, the age of the participant was found to be significantly associated variables that determine time to first optimal glycemic control. The study showed that, the time needed to reach first optimal glycemic control is longer among clients of age group $>10-14$ years followed by the age group 6-10 years compared to clients in the age group $<=5$ years $(\mathrm{AHR}=0.324,95 \% \mathrm{Cl}=0.192-0.546)$, indicating that for children older than 10 years, the rate of achieving optimal glycemic control decreases as age increases which is in line with study done in Tanzania ,Bulgaria, Iraq, Taiwan and Jordan $(26,46,47,49,50)$. This can be due to the fact that As a child develops, he/she under goes a varieties of physical and life style changes(24). In addition to this, it can be also due to hormonal effect at pubertal age of the child and decline in parental supervision over different clinical aspects of diabetic care in the adolescents $(46,50)$.

Weight of the client also significantly associated with time to first optimal glycemic control. Rate of glycemic achievement decreases by $3.6 \%$ as weight increase by one unit which means the weight of the client is 0.964 times less likely associated with optimal glycemic achievement rate. This could be due to, weight gain may contribute to increased insulin resistance and cardio metabolic risk such as increased dyslipidemia and blood pressure(62).It is in line with another controlled study among T1DM patients which stated previously as "normal weight preschool children have better glycemic control than age matched overweight children $(63,64)$."It can significantly implies that, body weight status may impede achievement of glycemic targets with in the expected time in this group of patients. Therefore, having regular exercise which is non-strenuous can be encouraged. The recommendation is supported by the study conducted in United Kingdom and the authors of International society of pediatrics and adolescents diabetes (ISPAD) guide line revised since $2018 \mathrm{GC}(6,34)$.

Dose of insulin at initiation of treatment increases first optimal glycemic achievement rate by 1.053 times as dose of insulin increases by one unit. This finding is supported by the study done in many countries such as India, china, Germany, Austria, and Luxembourg (6670).

This study also showed that, primary care giver during the follow up period was significantly associated with optimal glycemic control. Especially those clients whose care giver mother and father was two times more likely associated with first optimal glycemic control as compared with clients supported by their mothers alone. The finding was supported by the study conducted in Tanzania and middle east $\operatorname{Jordan}(32,50)$.

In regard to adherence to diabetic care, those clients with adherence had 9.7 fold of instantaneous chance of increasing their glycemic achievement rate as compared with those clients with no adherence to wards their diabetic management. Which is in line with the study conducted in Ethiopia entitled with incidence of diabetic keto acidosis and its predictors among type one diabetic children

(31).Correspondingly, those clients well adhered to Diet counseling specifically on food pyramid and non-refined carbohydrate utilization were found to have increasing their glycemic achievement rate by 2.4 folds as compared with those clients with no habit of practicing healthy diet at home and the finding is in line with the study conducted in Uganda $(35,54,64)$.

Duration of diabetes was also significantly associated with time to first optimal glycemic control in this study. Those clients living with diabetes for more than or equal to four years were $35.8 \%$ times less likely to achieve optimal glycemic control as compared with clients who were living with diabetes less than two years. This could be due to age maturation with advancement of the disease following to diabetic duration as it was explained above $(24,46,50)$. This finding is similar with the study done in Tanzania(31) but different with study done in cameron(75).

In addition to the above factors, having comorbid illness is another important predictors that can affect time to optimal glycemic control. The rate of achieving optimal glycemic control among clients with history of comorbid illness were $27.8 \%$ times less likely as compared with clients with no comorbid illness. This is because having comorbid illness has an influence on diabetes disease progress with impairment of glucose metabolism possibly lead to deterioration of glycemic control. Comorbid illness such as infection might also cause high level of counteracting hormones which triggering an episode of hyperglycemia and could also be due to the effect of taking many drugs which can lead to drug interaction and also can decrease drug adherence which interferes with drug effectiveness. This finding is in line with the studies conducted in Saudi Arabia, Brazil and university of California, San Francisco(18, 57-60).

\section{Strength and Limitation of the Study}

\section{Strength of the study}

Since the data were collected from two referral hospitals, the finding can have more power in regard to generalizability.

Page 9/27 


\section{Limitation of the study}

Since the data were collected from medical records, variables like parental socio economic factors cannot be addressed through card review which may affect the outcome of the study.

Fasting blood glucose level (FBG) measurements obtained from medical records might be subjected to measurement errors that lead to underestimated or overestimated of the result. However, effort was made to overcome this issues by taking the mean value of three month consecutive value of FBG measurements.

\section{Conclusion And Recommendation}

The median survival time to first optimal glycemic control in this study was long compared to other studies. Age, weight, primary care giver, insulin dose, duration of diabetes, adherence, and carbohydrate counting including history of comorbidity were determinant factors. Therefore, clinicians should advice weight reduction, increase the dose of insulin during initial treatment, counsel their parents about adherence of insulin drug and auditing their children diet as prescription helps to reduce the length of glycemic control.

\section{Abbreviations}

ADA: American Diabetic Association; BGM: Blood Glucose Monitoring; CGM: Continuous Glucose Monitoring; DCCT: Diabetes Control and Complication Trial; DM: Diabetes Mellitus; EDIC: Epidemiology of Diabetes Interventions and Complications; FBS: Fasting Blood Glucose; HbA1c: Glycated Hemoglobin A1C; IDF: International Diabetic Federation; ISPAD: International Society of Pediatrics and Adolescent Diabetes; NCDs: Non Communicable Diseases; SMBG: Self-Monitoring of Blood Glucose; SSA: Sub Saharan Africa; T1DM: Type 1 Diabetes Mellitus; URTI: Upper Respiratory Tract Infection; WHO: World Health Organization; EMoH: Ethiopian Ministry Of Health

\section{Declarations}

\section{Ethical approval and consent to participate}

Ethical clearance and approval were obtained from the institutional review board (IRB) of Bahir Dar University (IRB number 01008).Written supportive letter was taken from pediatrics department of the hospitals on behalf of the patients. This study had no any danger or negative consequences for the study participants. Medical record numbers were used for the data collection and personal identifiers of the client were not used in this research report. Access to collected information was limited to the principal investigator and confidentiality had preserved throughout the time.

\section{Consent for publication}

Not applicable

\section{Availability of data and materials}

Data will be available upon consortium approval.

\section{Competing interests}

All authors declared that they have no competing interests.

\section{Funding}

For this research the principal investigator $(\mathrm{PI})$ receive grants from Haramaya University as funding agency.

\section{Authors' contribution}

Fentahun Meseret had a substantial contribution from conception to the acquisition of the data. All the authors had a great contribution to the study design, analysis, and interpretation of the findings. Fentahun Meseret drafted the manuscript. All authors revised the drafted manuscript carefully for important intellectual contents. All authors read and approved the final manuscript. 
Our earnest gratitude goes to institutional review board (IRB) of Bahir Dar University for their proper review and approval of this paper. We are very happy to be in a position to thank to Haramaya University College of medicine and health science for funding

We would like to extend my acknowledgment to Felege Hiwot and Tibebe Ghion specialized hospital staffs for their cooperation when we were in need of information related to this research writing.

Our sincere gratitude and appreciation forward data collectors and participants without whom it would not be realized.

\section{Authors' information}

${ }^{1}$ Haramaya University, college of health and medical science, school of nursing, and Midwifery P.O. Box 235, Harar, Ethiopia. ${ }^{2}$ Bahirdar University, College of Health and Medical Science, School of Allied Health Science, P.O.Box 79, Bahir dar, Ethiopia.

\section{References}

1. OMS. Global Report on Diabetes. Isbn [Internet]. 2016;978:6-86. Available from: http://www.who.int/about/licensing/copyright_form/index.html\%0Ahttp://www.who.int/about/licensing/copyright_form/index.html \%0Ahttps://apps.who.int/iris/handle/10665/204871\%0Ahttp://www.who.int/about/licensing/accessed date12/17/2020

2. Care D, Suppl SS. Children and adolescents: Standards of medical care in diabetes- 2020. Diabetes Care. 2020;43(January):S16382. https://doi.org/10.2337/dc20-S013/accessed date 12/172020

3. Leulseged TW, Ayele BT. Time to optimal glycaemic control and prognostic factors among type 2 diabetes mellitus patients in public teaching hospitals in Addis Ababa, Ethiopia. PLoS One [Internet]. 2019;14(7):1-12. Available from: http://dx.doi.org/10.1371/journal.pone.0220309

4. Driscoll KA, Johnson SB, Wang Y, Wright N, Deeb LC. Blood Glucose Monitoring Before and After Type 1 Diabetes Clinic Visits. J Pediatr Psychol. 2019;44(1):32-9.

5. Cheneke W, Suleman S, Yemane T, Abebe G. Assessment of glycemic control using glycated hemoglobin among diabetic patients in Jimma University specialized hospital, Ethiopia. BMC Res Notes. 2016;9(1):1-10.

6. DiMeglio LA, Acerini CL, Codner E, Craig ME, Hofer SE, Pillay K, et al. ISPAD Clinical Practice Consensus Guidelines 2018: Glycemic control targets and glucose monitoring for children, adolescents, and young adults with diabetes. Pediatr Diabetes. 2018;19(July):105-14. https://onlinelibrary.wiley.com/doi/full/10.1111/pedi.12737/accessed date12/17/2020

7. Shah AS, Nadeau KJ. The changing face of paediatric diabetes. Diabetologia. 2020;63(4):683-91.

8. Bozkaya G, Ozgu E, Karaca B. The association between estimated average glucose levels and fasting plasma glucose levels. Clinics. 2010;65(11):1077-80.

9. L. N, B. A, W. M, K. P. Determinants of outcome of children with type 1 diabetes in Cameroon. Horm Res Paediatr [Internet]. 2015;84:185. Available from: http://www.embase.com/search/results? subaction=viewrecord\&from=export\&id=L72085656\%0Ahttp://dx.doi.org/10.1159/000437032

10. Ramírez-Mendoza F, González JE, Gasca E, Camacho M, Cruz M V., Caraveo D, et al. Time in range and HbA1C after 6 months with a multidisciplinary program for children and adolescents with diabetes mellitus, real world data from Mexico City. Pediatr Diabetes. 2020;21(1):61-8.

11. Musenge EM, Michelo C, Mudenda B, Manankov A. Glycaemic Control and Associated Self-Management Behaviours in Diabetic Outpatients: A Hospital Based Observation Study in Lusaka, Zambia. J Diabetes Res. 2016;2016.

12. Adamu Y, Garba KM, YAU S, Ya'u J. Glycemic Control and its Predictors among Diabetic Patients Attending a Tertiary Hospital in Nigeria: A Retrospective Observational Study. J Biomed Anal. 2020;3(1):13-25.

13. Shibeshi MS, Fantahun B, Kebede T, Tilahun B. Pediatric diabetic retinopathy: experience of a tertiary hospital in Ethiopia. BMC Res Notes. 2016;1-6.

14. Niba LL, Aulinger B, Mbacham WF, Parhofer KG. Predictors of glucose control in children and adolescents with type 1 diabetes: Results of a cross-sectional study in Cameroon. BMC Res Notes. 2017;10(1):1-10.

15. Yazidi M, Chihaoui M, Chaker F, Rjeb O, Slimane H. Factors Predicting Glycemic Control in Type 1 Diabetic Patient. Open Med J. 2016;3(1):153-8.

16. Abebe SM, Berhane Y, Worku A, Alemu S, Mesfin N. Level of sustained Glycemic control and associated factors among patients with diabetes mellitus in Ethiopia: A hospital-based cross-sectional study. Diabetes, Metab Syndr Obes Targets Ther. 2015;8:65-71. 
17. Gebreyohannes EA, Netere AK, Belachew SA. Glycemic control among diabetic patients in Ethiopia: A systematic review and metaanalysis. PLoS One [Internet]. 2019;14(8):1-14. Available from: http://dx.doi.org/10.1371/journal.pone.0221790

18. Andrade CS, Ribeiro GS, Santos CAST, Neves RCS, Moreira ED. Factors associated with high levels of glycated haemoglobin in patients with type 1 diabetes: A multicentre study in Brazil. BMJ Open. 2017;7(12):1-10.

19. Mutyambizi C, Pavlova M, Hongoro C, Groot W. Inequalities and factors associated with adherence to diabetes self-care practices amongst patients at two public hospitals in Gauteng, South Africa. BMC Endocr Disord. 2020;20(1):1-10.

20. Seth A. Challenges of Achieving an Optimum Glycemic Control in Children with Type 1 Diabetes in India. Indian J Pediatr. 2020;87(7):491-2.

21. Kangin M, Talay MN, Tanriverdi Yilmaz S, Unal E, Demiral M, Asena M, et al. A Retrospective Analysis of Children and Adolescents With Diabetic Ketoacidosis in the Intensive Care Unıt: Is It Significant that the Blood Ketone Level Becomes Negative in Diabetic Ketoacidosis? Cureus. 2020;12(10):1-8.

22. Zurita Cruz JN, Dosta Martínez GE, Villasís Keever MÁ, Rivera Hernández A de J, Garrido Magaña E, Nishimura Meguro E. Pacientes pediátricos con diabetes tipo 1: crecimiento y factores asociados con su alteración. Bol Med Hosp Infant Mex. 2016;73(3):174-80.

23. Carneiro VL, Fraiz FC, Ferreira F de M, Pintarelli TP, Oliveira ACB, Boguszewski MC da S. The influence of glycemic control on the oral health of children and adolescents with diabetes mellitus type 1. Arch Endocrinol Metab. 2015;59(6):535-40.

24. Smokovski I. Managing Diabetes in Low Income Countries. Manag Diabetes Low Income Ctries. 2021;

25. Tsadik AG, Atey TM, Nedi T, Fantahun B, Feyissa M. Effect of Insulin-Induced Lipodystrophy on Glycemic Control among Children and Adolescents with Diabetes in Tikur Anbessa Specialized Hospital, Addis Ababa, Ethiopia. J Diabetes Res. $2018 ; 2018$.

26. Mclarty RP, Alloyce JP, Chitema GG, Msuya LJ. Glycemic control , associated factors , acute complications of Type 1 Diabetes Mellitus in children, adolescents and young adults in Tanzania. 2020;(July):1-8.

27. Msanga D, Reis K, Kayange N, Bakalemwa R, Kidenya B, Hau D, et al. Diabetic microvascular complications among children and adolescents in northwestern Tanzania: A cross-sectional study. Ann Glob Heal. 2020;86(1):1-8.

28. Al-fraik NGS, Abdulrraziq SM, Najem MSM. Demographic and Clinical Characteristics of Type I Diabetes Mellitus at Tobruck Pediatric Intensive Care Unit. Middle East J Appl Sci. 2020;304-12.

29. Shiferaw WS, Akalu TY, Aynalem YA. Chronic Kidney Disease among Diabetes Patients in Ethiopia: A Systematic Review and MetaAnalysis. Int J Nephrol. 2020;2020.

30. Collin A.Ross. improved a1c readings for diabetic patients who receive feedback via text messaging. j chem inf model. 2017;53(9):1689-99.

31. Zeleke H, Murugan R, Wondwossen K. Incidence and predictors of diabetic ketoacidosis among children with diabetes in west and east gojjam zone referral hospitals north west Ethiopia ,. 2019;

32. Noorani M, Ramaiya K, Manji K. Glycaemic control in type 1 diabetes mellitus among children and adolescents in a resource limited setting in Dar es Salaam- Tanzania. BMC Endocr Disord [Internet]. 2016;16(1):1-8. Available from: http://dx.doi.org/10.1186/s12902-016-0113-y

33. Hannonen R, Aunola K, Eklund K, Ahonen T. Maternal parenting styles and glycemic control in children with type 1 diabetes. Int J Environ Res Public Health. 2019;16(2).

34. Taylor GS, Smith K, Capper TE, Scragg JH, Bashir A, Flatt A, et al. Postexercise glycemic control in type 1 diabetes is associated with residual b-cell function. Diabetes Care. 2020;43(10):2362-70.

35. Seckold R, Howley P, King BR, Bell K, Smith A, Smart CE. Dietary intake and eating patterns of young children with type 1 diabetes achieving glycemic targets. BMJ Open Diabetes Res Care. 2019;7(1).

36. Al Zahrani AM, Al Shaikh A. Glycemic Control in Children and Youth With Type 1 Diabetes Mellitus in Saudi Arabia. Clin Med Insights Endocrinol Diabetes [Internet]. 2019;12. Available from: https://doi.org/10.1177/1179551418825159

37. Karges B, Schwandt A, Heidtmann B, Kordonouri O, Binder E, Schierloh U, et al. Association of insulin pump therapy vs insulin injection therapy with severe hypoglycemia, ketoacidosis, and glycemic control among children, adolescents, and young adults with type 1 diabetes. JAMA - J Am Med Assoc. 2017;318(14):1358-66.

38. Patton SR, Noser AE, Youngkin EM, Majidi S, Clements MA, Al PET. Early Initiation of Diabetes Devices Relates to Improved Glycemic Control in Children with Recent-Onset Type 1 Diabetes Mellitus. 2019;21(7):379-84.

39. Hood KK, Ph D. Predictors of deteriorations in diabetes management and control in adolescents with type 1 diabetes. $2015 ; 52(1): 28-34$.

Page 12/27 
40. Ngwiri T, Were F, Predieri B, Ngugi P, lughetti L. Glycemic Control in Kenyan Children and Adolescents with Type 1 Diabetes Mellitus. Int J Endocrinol. 2015;2015.

41. Sarfo-Kantanka O, Sarfo FS, Ansah EO, Eghan B, Ayisi-Boateng NK, Acheamfour-Akowuah E. Secular trends in admissions and mortality rates from diabetes mellitus in the central belt of Ghana: A 31-year review. PLoS One [Internet]. 2016;11(11):1-14. Available from: http://dx.doi.org/10.1371/journal.pone.0165905

42. Uleanya ND, Aniwada EC, Nwokoye IC, Ndu IK, Eke CB. Relationship between Glycemic Levels and Treatment Outcome among Critically III Children admitted into Emergency Room in Enugu. BMC Pediatr. 2017;17(1):1-7.

43. Amos M, Gladys C, Sandeni C, Alfred J, Levina M, Jedeni B, et al. Complications and Glycaemic Control of Type 1 Diabetes Mellitus amongst Children Aged 5 to 19 Years Attending Diabetic Clinic at Kamuzu Central Hospital In Malawi. Int J Diabetes Clin Res. 2020;7(1).

44. Teklehaimanot berhane fseha, berhe abadi kidanemariam, welearegawi gebrehiwet gebremariam. Poor glycemic control and associated factors among diabetic patients in Ethiopia; A Systemic review and meta-analysis. Poor glycemic Control Assoc factors among Diabet patients Ethiop A Syst Rev meta-analysis. 2019;19004986.

45. Dumrisilp T, Supornsilchai V, Wacharasindhu S, Aroonparkmongkol S, Sahakitrungruang T. Factors associated with glycemic control in children and adolescents with type 1 diabetes mellitus at a tertiary-care center in Thailand: A retrospective observational study. Asian Biomed. 2017;11(6):443-50.

46. Rewers MJ, Pillay K, de Beaufort C, Craig ME, Hanas R, Acerini CL, et al. Assessment and monitoring of glycemic control in children and adolescents with diabetes. Pediatr Diabetes. 2014;15(SUPPL.20):102-14.

47. Governorate S. Original Article Factors Affecting Glycemic Control in Type 1 Diabetes Mellitus among. 2019;8(2).

48. Setoodeh A, Mostafavi F, Rabbani A, Hedayat T. Female Sex as a Risk Factor for Glycemic Control and Complications in Iranian Patients with Type One Diabetes Mellitus. 2011;21(3):373-8.

49. Hsiao YT, Cheng WC, Liao WC, Lin CL, Shen TC, Chen WC, et al. Type 1 diabetes and increased risk of subsequent asthma: A nationwide population-based cohort study. Med (United States). 2015;94(36):1-6.

50. Alassaf A, Odeh R, Gharaibeh L, Ibrahim S, Ajlouni K. Personal and clinical predictors of poor metabolic control in children with type 1 diabetes in Jordan. J Diabetes Res. 2019;2019:15-8.

51. A AlAgha M, M Majdi W, Aljefri HM, Abdelfattah Ali M, Alagha AE, Abd Elhameed IA, et al. Effect of Parents' Educational Level and Occupational Status on Child Glycemic Control. J Patient Care. 2017;03(02):2-4.

52. Kajee Z, Harvey J, Zöllner EW. The impact of a diabetes care team on the glycaemic control of paediatric and adolescent patients with type 1 diabetes mellitus at tygerberg children's hospital. SAJCH South African J Child Heal. 2019;13(1):12-6.

53. Haynes A, Hermann JM, Clapin H, Hofer SE, Karges B, Jones TW, et al. Decreasing trends in mean HbA1c are not associated with increasing rates of severe hypoglycemia in children: A longitudinal analysis of two contemporary population-based pediatric type 1 diabetes registries from Australia and Germany/Austria between 1995 . Diabetes Care. 2019;42(9):1630-6.

54. Ndahura NB, Munga J, Kimiywe J, Mupere E. Caregivers ' Nutrition Knowledge and Dietary Intake of Type 1 Diabetic Children Aged 3 - 14 Years in Uganda. 2021;127-37.

55. Sildorf SM, Breinegaard N, Lindkvist EB, Tolstrup JS, Boisen KA, Teilmann GK, et al. Poor metabolic control in children and adolescents with type 1 diabetes and psychiatric comorbidity. Diabetes Care. 2018;41(11):2289-96.

56. Schoenaker DAJM, Simon D, Chaturvedi N, Fuller JH, Soedamah-Muthu SS. Glycemic control and all-cause mortality risk in type 1 diabetes patients: The EURODIAB prospective complications study. J Clin Endocrinol Metab. 2014;99(3):800-7.

57. Krzewska A, Ben-Skowronek I. Effect of Associated Autoimmune Diseases on Type 1 Diabetes Mellitus Incidence and Metabolic Control in Children and Adolescents. Biomed Res Int. 2016;2016.

58. Al-Agha AE, Alafif M, Abd-Elhameed IA. Glycemic control, Complications, and associated autoimmune diseases in children and adolescents with type 1 diabetes in Jeddah, Saudi Arabia. Saudi Med J. 2015;36(1):26-31.

59. Calliari LE, Almeida FJ, Noronha RM. Infections in children with diabetes. J Pediatr (Rio J). 2020;96:39-46.

60. Chiang JL, Maahs DM, Garvey KC, Hood KK, Laffel LM, Weinzimer SA, et al. Type 1 Diabetes in Children and Adolescents: A Position Statement by the American Diabetes Association. 2018;41(September):2026-44.

https://care.diabetesjournals.org/content/41/9/2026.article-info/accessed date 12/17/2020

61. Mbbs SAl, Edin F, Mbbs GA, Bajaj HS, Mb SR. Targets for Glycemic Control Diabetes Canada Clinical Practice Guidelines Expert Committee. 2018;42:42-6. https://guidelines.diabetes.ca/cpg/chapter34/accessed date1/162021

Page 13/27 
62. Jaja TC, Yarhere IE. Dyslipidaemia in Nigerian Children and Adolescents with Diabetes Mellitus: Prevalence and Associated Risk Factors. Int J Diabetes Metab. 2019;25(1-2):45-51.

63. T.R. Nansel, PhD1, L.M. Lipsky, PhD1, and R.J. lannotti P. Cross-sectional and longitudinal relationships of body mass index with glycemic control in children and adolescents with type 1 diabetes mellitus. 2014;100(1):126-32.

64. Kerkeni L, Ruano P, Delgado LL, Picco S, Villegas L, Tonelli F, et al. Nutritional Management in Type 1 Diabetes Mellitus. Intech [Internet]. 2016;(tourism):13. Available from: https://www.intechopen.com/books/advanced-biometric-technologies/livenessdetection-in-biometrics

65. Teni DA, Enquoselassie F, Atsmegiorgis C. Survival analysis of diabetes mellitus patients using parametric, non-parametric and semi-parametric approaches: Addis Ababa , Ethiopia. Ethiop e-Journal Res Innov Foresight. 2015;7(1):20-39.

66. Wangnoo SK. Initiating insulin therapy in children and adolescents with type 1 diabetes mellitus. Indian J Endocrinol Metab. 2015;19(7):S68-70.

67. Krhač M, Lovrenčić MV. Update on biomarkers of glycemic control. World J Diabetes. 2019;10(1):1-15.

68. Thabit H, Prabhu JN, Mubita W, Fullwood C, Azmi S, Urwin A, et al. Use of Factory-Calibrated Real-time Continuous Glucose Monitoring Improves Time in Target and HbA1c in a Multiethnic Cohort of Adolescents and Young Adults With Type 1 Diabetes: The MILLENNIALS Study. Diabetes Care. 2020;43(10):2537-43.

69. Maiorino MI, Signoriello S, Maio A, Chiodini P, Bellastella G, Scappaticcio L, et al. Effects of continuous glucose monitoringonmetricsofglycemic control in diabetes: A Systematic Review with Meta-analysis of Randomized Controlled Trials. Diabetes Care. 2020;43(5):1146-56.

70. Klatman EL, Ogle GD. Access to insulin delivery devices and glycated haemoglobin in lower-income countries. World J Diabetes. 2020;11(8):358-69.

71. DeSalvo DJ, Miller KM, Hermann JM, Maahs DM, Hofer SE, Clements MA, et al. Continuous glucose monitoring and glycemic control among youth with type 1 diabetes: International comparison from the T1D Exchange and DPV Initiative. Pediatr Diabetes. 2018;19(7):1271-5.

72. Zuberi Z, Sauli E, Cun L, Deng J, Li WJ, He XL, et al. Insulin-delivery methods for children and adolescents with type 1 diabetes. Ther Adv Endocrinol Metab [Internet]. 2020;11:1-13. Available from: https://doi.org/10.1177/2042018820906016

73. Djonou C, Tankeu AT, Dehayem MY, Tcheutchoua DN, Mbanya JC, Sobngwi E. Glycemic control and correlates in a group of sub Saharan type 1 diabetes adolescents. BMC Res Notes [Internet]. 2019;1-5. Available from: https://doi.org/10.1186/s13104-0194054-1

74. Nuche-Berenguer B, Kupfer LE. Erratum to 'Readiness of Sub-Saharan Africa Healthcare Systems for the New Pandemic, Diabetes: A Systematic Review'. J Diabetes Res. 2018;2018:3419290.

75. Djonou C, Tankeu AT, Dehayem MY, Tcheutchoua DN, Mbanya JC, Sobngwi E. Glycemic control and correlates in a group of sub Saharan type 1 diabetes adolescents 11 Medical and Health Sciences 1117 Public Health and Health Services. BMC Res Notes [Internet]. 2019;12(1):1-5. Available from: https://doi.org/10.1186/s13104-019-4054-1

76. Taha Z, Eltoum Z, Washi S. Predictors of glucose control in children and adolescents with type 1 diabetes: Results of a crosssectional study in Khartoum, Sudan. Open Access Maced J Med Sci. 2018;6(11):2035-9.

77. Ganu D. Increasing Incidence and Prevalence of Type 1 Diabetes in Children Under 20 Years of Age between 1999-2019 in SubSaharan Africa: A Systematic Review. 2020;3(1):1-8.

78. Home P, Haddad J, Latif ZA, Soewondo P, Benabbas Y, Litwak L, et al. Comparison of national/regional diabetes guidelines for the management of blood glucose control in non-western countries. Diabetes Ther. 2013;4(1):91-102.

79. Hitt JM. Hemoglobin A1C and the Diagnosis of Diabetes and Prediabetes in Children and Adolescents. Hemoglobin A1c Diagnosis Diabetes Prediabetes Child Adolesc. 2014;67 p.

80. MOH. Guidelines on Clinical and Programmatic Management of Major Non Communicable Diseases. 2016;220. https://extranet.who.int/ncdccs/Data/ETH_D1_National\%20NCD\%20Guideline/accessed date 12/17/2020

\section{Tables}

Table 1: sociodemographic and institution related variable with censuring and event status among type 1 diabetic clients, Bahir Dar, Ethiopia, 2021(n=385) 


\begin{tabular}{|c|c|c|c|c|}
\hline \multirow[t]{3}{*}{ Variables } & \multirow[t]{3}{*}{ Category } & \multicolumn{3}{|c|}{ Event and censured status } \\
\hline & & \multicolumn{3}{|r|}{ Total } \\
\hline & & No. of event & No.of censured & \\
\hline \multirow[t]{3}{*}{ Age group in years } & $<=5$ & $83(68 \%)$ & $39(32 \%)$ & $122(31.7 \%)$ \\
\hline & $>5-10$ & $79(85.9 \%)$ & $13(14.1 \%)$ & $92(23.9 \%)$ \\
\hline & $>10-14$ & $114(66.7 \%)$ & $57(33.3 \%)$ & $171(44.4 \%)$ \\
\hline \multirow[t]{2}{*}{ Sex } & Male & $147(72 \%)$ & $57(27.9 \%)$ & $204(53 \%)$ \\
\hline & Female & $129(71.3 \%)$ & $52(28.7 \%)$ & $181(47 \%)$ \\
\hline \multirow[t]{2}{*}{ Resident } & Urban & $105((77.2 \%)$ & $31(22.8 \%)$ & $136(35.3 \%)$ \\
\hline & Rural & $171(68.7 \%)$ & $78(31.3 \%)$ & $249(64.7 \%)$ \\
\hline \multirow[t]{2}{*}{ Number of clinic visit during the last year of follow up } & $<=4$ & $169(66.3 \%)$ & $86(33.7 \%)$ & $255(66.2 \%)$ \\
\hline & $>4$ & $107(82.3 \%)$ & $23(17.7 \%)$ & $130(33.8 \%)$ \\
\hline
\end{tabular}

Table 2: Diabetes related variable with censuring and event status among type 1 diabetic clients, Bahir Dar, Ethiopia, 2021(n=385) 


\begin{tabular}{|c|c|c|c|c|}
\hline \multirow[t]{2}{*}{ Variables } & \multirow[t]{2}{*}{ Category } & $\begin{array}{l}\text { Event and censured } \\
\text { status }\end{array}$ & \multicolumn{2}{|l|}{ total } \\
\hline & & No. of event & $\begin{array}{l}\text { No.of } \\
\text { censured }\end{array}$ & \\
\hline \multirow[t]{2}{*}{ History of diabetes related complication } & NO & $49(76.6 \%)$ & $15(23.4 \%)$ & $64(16.6 \%)$ \\
\hline & Yes & $227(70.7 \%)$ & $94(29.3 \%)$ & $321(83.4 \%)$ \\
\hline \multirow[t]{2}{*}{ DKA } & NO & $53(72.6 \%)$ & $20(27.4 \%)$ & $73(19 \%)$ \\
\hline & Yes & $223(71.5 \%)$ & $89(28.5 \%)$ & $312(81 \%)$ \\
\hline \multirow[t]{2}{*}{ Hypoglycemia } & NO & $211(68.3 \%)$ & $98(31.7 \%)$ & $309(80.3 \%)$ \\
\hline & Yes & $65(85.5 \%)$ & $11(14.5 \%)$ & 76(19.7\%) \\
\hline \multirow[t]{2}{*}{ Chronic complication } & NO & $274(71.7 \%)$ & $108(28.3 \%)$ & $382(99.2 \%)$ \\
\hline & Yes & $2(66.7 \%)$ & $1(33.3 \%)$ & $3(0.8 \%)$ \\
\hline \multirow[t]{2}{*}{ Other complication* } & NO & $259(71.9 \%)$ & $101(28 \%)$ & $360(93.5 \%)$ \\
\hline & Yes & $12(63.2 \%)$ & $7(36.8 \%)$ & $19(4.9 \%)$ \\
\hline \multirow[t]{2}{*}{ More than one complication } & NO & $245(72 \%)$ & $95(27.9 \%)$ & $340(88.3 \%)$ \\
\hline & Yes & $31(68.9 \%)$ & 14(31.1\%) & $45(11.7 \%)$ \\
\hline \multirow[t]{2}{*}{ Diabetes related hospitalization } & NO & $52(74.3 \%)$ & $18(25.7 \%)$ & $70(18.2 \%)$ \\
\hline & Yes & $224(71.1 \%)$ & $91(28.9 \%)$ & $315(81.8 \%)$ \\
\hline \multirow[t]{3}{*}{ Insulin Regimen } & $\begin{array}{l}\text { Mix(regular } \\
\text { \&lent) }\end{array}$ & $154(63.6 \%)$ & $88(36.4 \%)$ & $242(62.9 \%)$ \\
\hline & NPH \&regular & $70(90.9 \%)$ & $7(9 \%)$ & $77(20 \%)$ \\
\hline & NPH only & $52(78.8 \%)$ & $14(21.2 \%)$ & $66(17.1 \%)$ \\
\hline \multirow{2}{*}{$\begin{array}{l}\text { Non Compliance (dose omission, drug skipping, } \\
\text { inappropriate insulin storage) }\end{array}$} & NO & $219(85.5 \%)$ & $37(14.5 \%)$ & $256(66.5 \%)$ \\
\hline & Yes & $56(43.8 \%)$ & 72(56.3\%) & $128(33.2 \%)$ \\
\hline \multirow[t]{3}{*}{ Duration of diabetes } & $<2$ & $75(0.5 \%)$ & $75(0.5 \%)$ & $150(39 \%)$ \\
\hline & {$[2-4)$} & $80(80.8 \%)$ & 19(19.2\%) & $99(25.7 \%)$ \\
\hline & $>=4$ & $121(89 \%)$ & $15(11 \%)$ & 136(35.3\%) \\
\hline \multirow[t]{2}{*}{ Adherence to diabetic care } & NO & $91(46.7 \%)$ & 104(53.3\%) & $195(50.6 \%)$ \\
\hline & Yes & $185(97.4 \%)$ & $5(2.6 \%)$ & $190(49.4 \%)$ \\
\hline \multirow[t]{2}{*}{ Family history of diabetes mellitus } & NO & $238(71.7 \%)$ & $94(28.3 \%)$ & $332(86.2 \%)$ \\
\hline & Yes & $38(71.7 \%)$ & $15(28.3 \%)$ & $53(13.8 \%)$ \\
\hline
\end{tabular}

*other complication includes insulin injection site swelling together with lipohypertrophy and dystrophy

Table 3: comorbid illness related variable with censuring and event status among type 1 diabetic clients, Bahir Dar city public referral hospitals,Northwest,Ethiopia,2021(n=385) 


Variables Category Event and censured status total

\begin{tabular}{|c|c|c|c|c|}
\hline & & \multirow{2}{*}{\multicolumn{2}{|c|}{ No of event No of censured }} & \\
\hline & & & & \\
\hline \multirow[t]{2}{*}{ History of comorbid illness } & NO & $87(74.4 \%)$ & $30(25.6 \%)$ & $117(30.4 \%)$ \\
\hline & Yes & $189(70.5 \%)$ & $79(29.5 \%)$ & $268(69.6 \%)$ \\
\hline \multirow[t]{2}{*}{ Cardio vascular disease(CVD) } & NO & $273(72 \%)$ & $106(28 \%)$ & $379(98.4 \%)$ \\
\hline & Yes & $3(50 \%)$ & $3(50 \%)$ & $6(1.6 \%)$ \\
\hline \multirow[t]{2}{*}{ Hypertension(HTN) } & NO & $272(71.8 \%)$ & $107(28.2 \%)$ & $379(98.4 \%)$ \\
\hline & Yes & $4(66.7 \%)$ & $2(33.3 \%)$ & $6(1.6 \%)$ \\
\hline \multirow[t]{2}{*}{ Urinary tract infection(UTI) } & NO & $244(73.5 \%)$ & $88(26.5 \%)$ & $332(86.2 \%)$ \\
\hline & Yes & $32(60.4 \%)$ & $21(39.6 \%)$ & $53(13.8 \%)$ \\
\hline \multirow[t]{2}{*}{ Pneumonia(CAP) } & NO & $234(72.4 \%)$ & $89(27.6 \%)$ & $323(83.9 \%)$ \\
\hline & Yes & $42(67.7 \%)$ & $20(32.3 \%)$ & $62(16.1 \%)$ \\
\hline \multirow[t]{2}{*}{ Upper respiratory tract infection(URTI) } & NO & $264(72.5 \%)$ & $100(27.5 \%)$ & $364(94.5 \%)$ \\
\hline & Yes & $15(60 \%)$ & $10(40 \%)$ & $25(6.5 \%)$ \\
\hline \multirow[t]{2}{*}{ Acute gastro enteritis(AGE) } & NO & $248(71.7 \%)$ & $98(28.3 \%)$ & $346(89.9 \%)$ \\
\hline & Yes & $28(71.8 \%)$ & $11(28.2 \%)$ & $39(10.1 \%)$ \\
\hline \multirow[t]{2}{*}{ Malnutrition } & NO & $191(71.5 \%)$ & $76(28.5 \%)$ & $267(69.4 \%)$ \\
\hline & Yes & $107(71.8 \%)$ & $42(28.2 \%)$ & $149(38.7 \%)$ \\
\hline \multirow[t]{2}{*}{ Autoimmune disease } & NO & $270(72.2 \%)$ & $104(27.8 \%)$ & $374(97.1 \%)$ \\
\hline & Yes & $6(54.5 \%)$ & $5(45.5 \%)$ & $11(2.9 \%)$ \\
\hline \multirow[t]{2}{*}{ Tuberculosis(TB) } & NO & $273(72 \%)$ & $106((28 \%)$ & $379(98.4 \%)$ \\
\hline & Yes & $3(50 \%)$ & $3(50 \%)$ & $6(1.6 \%)$ \\
\hline \multirow[t]{2}{*}{ Meningitis } & NO & $274(73 \%)$ & $101(26.9 \%)$ & $375(97.4 \%)$ \\
\hline & Yes & $2(20 \%)$ & $8(80 \%)$ & $10(2.6 \%)$ \\
\hline \multirow[t]{2}{*}{ Malaria } & NO & $268(72 \%)$ & $104(28 \%)$ & $372(96.6 \%)$ \\
\hline & Yes & $8(61.5 \%)$ & $5(38.5 \%)$ & $13(3.4 \%)$ \\
\hline \multirow[t]{2}{*}{ Fungal infection } & NO & $262(73.2 \%)$ & $96(26.8 \%)$ & $358(93 \%)$ \\
\hline & Yes & $14(51.9 \%)$ & $13(48.1 \%)$ & $27(7 \%)$ \\
\hline \multirow[t]{2}{*}{ More than one comorbid illness } & NO & $146(73 \%)$ & $54(27 \%)$ & $200(51.9 \%)$ \\
\hline & Yes & $130(70.3 \%)$ & $55(29.7 \%)$ & $185(48 \%)$ \\
\hline
\end{tabular}

Table 4: comparisons of optimal glycemic control among type 1 DM clients, Bahir Dar city public referral hospitals, Northwest, Ethiopia, 2021(n=385)

$\mathrm{X}^{2}$ :chi-square, DF: Degree of freedom, KG: kindergarten

Table 5:Test of proportional-hazards assumption by Schoen field residual test (Global test) among type 1 DM clients, Bahir Dar city 


\begin{tabular}{|c|c|c|c|c|c|c|}
\hline \multirow[t]{3}{*}{ Variables } & \multirow[t]{3}{*}{ Category } & \multicolumn{2}{|c|}{ Test of equality over groups } & & & \\
\hline & & \multirow{2}{*}{$\begin{array}{l}\text { Median } \\
\text { survival } \\
\text { time(months) }\end{array}$} & \multirow{2}{*}{$\begin{array}{l}\text { Mean survival } \\
\text { time(months) }\end{array}$} & \multicolumn{3}{|c|}{ Log rank } \\
\hline & & & & $x^{2}$ & DF & P-value \\
\hline \multirow[t]{4}{*}{ Age group in years } & $<=5$ & 6.8 & 8.5 & 6.05 & 2 & 0.0486 \\
\hline & $>5-10$ & 8 & 9.8 & & & \\
\hline & $>10-14$ & 8.5 & 10.2 & & & \\
\hline & Male & 8.5 & 9.9 & 0.92 & 1 & 0.3378 \\
\hline \multirow[t]{2}{*}{ Sex } & Female & 7.2 & 9.2 & & & \\
\hline & Urban & 7.6 & 9.6 & 0.02 & 1 & 0.8911 \\
\hline Resident & Rural & 8 & 9.6 & & & \\
\hline \multirow[t]{3}{*}{ Education status of children } & KG/not started & 7.1 & 8.9 & 11.23 & 2 & 0.0036 \\
\hline & Primary school & 9 & 10.6 & & & \\
\hline & High school & 14.8 & 13 & & & \\
\hline \multirow[t]{2}{*}{ Family history of diabetes } & NO & 7.8 & 8.7 & 0.28 & 1 & 0.5987 \\
\hline & Yes & 8 & 9.4 & & & \\
\hline \multirow[t]{2}{*}{ Number of clinic visit } & $<=4$ & 7.7 & 8.5 & 1.31 & 1 & 0.2521 \\
\hline & $>4$ & 8 & 9.4 & & & \\
\hline \multirow[t]{2}{*}{ Adherence to diabetic care } & NO & 14.9 & 10.9 & 131.75 & 1 & $<0.0001$ \\
\hline & Yes & 5.7 & 6.7 & & & \\
\hline \multirow[t]{3}{*}{ Insulin regimen } & $\begin{array}{l}\text { Mixed(lent } \\
\text { \&Regular) }\end{array}$ & 7.1 & 8.4 & 15.87 & 2 & 0.0004 \\
\hline & NPH\& Regular & 9.2 & 10.1 & & & \\
\hline & NPH only & 9.8 & 12.3 & & & \\
\hline \multirow[t]{3}{*}{ Duration of Diabetes in year } & $<2$ & 5.5 & 6.2 & 54.93 & 2 & $<0.0001$ \\
\hline & {$[2-4)$} & 8.6 & 10 & & & \\
\hline & $>=4$ & 11.1 & 11.4 & & & \\
\hline \multirow[t]{2}{*}{ Carbohydrate count } & NO & 10.2 & 11.1 & 40.26 & 1 & $<0.0001$ \\
\hline & Yes & 5.5 & 6.9 & & & \\
\hline \multirow[t]{2}{*}{ Noncompliance } & NO & 6.4 & 8.2 & 42.30 & 1 & $<0.0001$ \\
\hline & Yes & 14.8 & 14.9 & & & \\
\hline \multirow{2}{*}{$\begin{array}{l}\text { Diabetes related acute } \\
\text { complication }\end{array}$} & NO & 7.7 & 9.5 & 2.94 & 1 & 0.0862 \\
\hline & Yes & 8 & 9.6 & & & \\
\hline \multirow[t]{2}{*}{ Diabetic ketoacidosis } & NO & 6.2 & 9.5 & 0.12 & 1 & 0.7289 \\
\hline & Yes & 8 & 9.6 & & & \\
\hline \multirow[t]{2}{*}{ Chronic complication } & NO & 7.8 & 8.7 & 0.59 & 1 & 0.4434 \\
\hline & Yes & 12.1 & 18.5 & & & \\
\hline Other complication & NO & 7.8 & 9.5 & 1.02 & 1 & 0.3131 \\
\hline
\end{tabular}




\begin{tabular}{|c|c|c|c|c|c|c|}
\hline & Yes & 10.2 & 11.3 & & & \\
\hline \multirow[t]{2}{*}{ More than one complication } & NO & 7.8 & 9.3 & 0.21 & 1 & 0.6448 \\
\hline & Yes & 8.9 & 10 & & & \\
\hline \multirow[t]{2}{*}{ History of comorbidity } & NO & 6.3 & 8.3 & 10.85 & 1 & 0.0010 \\
\hline & Yes & 8.9 & 10.1 & & & \\
\hline \multirow[t]{2}{*}{ Wasting } & NO & 8.2 & 8.9 & 1.07 & 1 & 0.3003 \\
\hline & Yes & 6.8 & 8.6 & & & \\
\hline \multirow[t]{2}{*}{ Stunting } & NO & 7.8 & 8.8 & 0.15 & 1 & 0.7019 \\
\hline & Yes & 9.8 & 8.4 & & & \\
\hline \multirow[t]{2}{*}{ Cardio vascular disease } & NO & 7.8 & 8.8 & 0.01 & 1 & 0.9229 \\
\hline & Yes & 12.1 & 10.2 & & & \\
\hline \multirow[t]{2}{*}{ Pneumonia } & NO & 7.7 & 8.9 & 0.89 & & 0.3460 \\
\hline & Yes & 9 & 8.1 & & & \\
\hline \multirow[t]{2}{*}{ Acute gastro enteritis } & NO & 7.7 & 9.4 & 2.05 & 1 & 0.1524 \\
\hline & Yes & 10.2 & 11.5 & & & \\
\hline \multirow[t]{2}{*}{ More than one comorbid illness } & NO & 7.7 & 9.5 & 0.21 & 1 & 0.6448 \\
\hline & Yes & 8.7 & 9.7 & & & \\
\hline
\end{tabular}

public referral hospitals, Northwest, Ethiopia, 2021(n=385)

\begin{tabular}{|lllll|}
\hline Variables & Rho & $\mathrm{X}^{2}$ & DF & P-value \\
\hline Age & 0.03898 & 0.39 & 1 & 0.5310 \\
\hline Educational status of children & 0.06785 & 1.01 & 1 & 0.3138 \\
\hline Primary care giver & 0.13921 & 3.91 & 1 & 0.050 \\
\hline Weight the client & & 0.97 & 1 & 0.3253 \\
\hline Duration of diabetes & 0.01613 & 0.08 & 1 & 0.7784 \\
\hline Insulin regimen & 0.12133 & 2.82 & 1 & 0.0934 \\
\hline Dose of insulin & 0.07640 & 1.21 & 1 & 0.2715 \\
\hline Frequency of glycemic control & -0.00730 & 0.01 & 1 & 0.9230 \\
\hline Carbohydrate counting & 0.13800 & 3.28 & 1 & 0.0700 \\
\hline Exercise & 0.02123 & 0.09 & 1 & 0.7580 \\
\hline Noncompliance & 0.08636 & 1.37 & 1 & 0.2410 \\
\hline Adherence & -0.03696 & 0.25 & 1 & 0.6154 \\
\hline Diabetes related complication & 0.01547 & 0.06 & 1 & 0.8037 \\
\hline Comorbidity & -0.08886 & 1.89 & 1 & 0.1689 \\
\hline global test & 42.48 & & 19 & 0.5368 \\
\hline
\end{tabular}

Rho: spearman rank correlation coefficients, X2: chi Square, DF: Degree of freedom 
Table 6: Results for the final cox regression hazard model among type 1DM clients Bahir Dar city public referral hospitals,Northwest,Ethiopia,2021(n=385)

\begin{tabular}{|c|c|c|c|}
\hline Variable & $\mathrm{CHR}(95 \% \mathrm{Cl})$ & $\operatorname{AHR}(95 \% \mathrm{Cl})$ & P-value \\
\hline Insulin dose at initiation of Rx & $0.982(0.969-0.993) *$ & $1.053(1.029-1.078)$ & $<0.001 * *$ \\
\hline Weight of the client & $0.978(0.965-0.992) *$ & $0.964(0.939-0.989)$ & $0.005^{\star *}$ \\
\hline \multicolumn{4}{|l|}{ Age group in years at diagnosis } \\
\hline \multicolumn{4}{|l|}{$<=5 \circledast$} \\
\hline$>5-10$ & $0.802(0.587-1.097)$ & $0.926(0.619-1.384)$ & 0.707 \\
\hline$>10-14$ & $0.599(0.448-0.801) \star$ & $0.324(0.192-0.546)$ & $<0.001 * *$ \\
\hline \multicolumn{4}{|l|}{ Sex of the participant } \\
\hline \multicolumn{4}{|l|}{ Maleß } \\
\hline Female & $1.116(0.879-1.416)$ & & \\
\hline \multicolumn{4}{|l|}{ Resident } \\
\hline \multicolumn{4}{|l|}{ Urban® } \\
\hline Rural & $1.010(0.790-1.292)$ & & \\
\hline \multicolumn{4}{|l|}{ Primary care giver } \\
\hline \multicolumn{4}{|l|}{ Mother alone® } \\
\hline Mother and Father & $0.848(0.617-1.165)$ & $2.092(1.397-3.132)$ & $<0.001 * *$ \\
\hline Father alone & $0.824(0.493-1.378)$ & $1.171(0.631-2.171)$ & 0.617 \\
\hline Other & $0.685(0.475-0.988)^{\star}$ & $0.801(0.491-1.305)$ & 0.372 \\
\hline \multicolumn{4}{|l|}{ Educational status of children } \\
\hline \multicolumn{4}{|l|}{ K/not started® } \\
\hline Primary school & $0.746(0.527-1.057)$ & $0.868(0.574-1.314)$ & 0.505 \\
\hline High school & $0.684(0.471-0.992) \star$ & $1.333(0.745-2.386)$ & 0.333 \\
\hline
\end{tabular}

Table 7: Results for the final cox regression hazard model among type 1DM clients Bahir Dar city public referral hospitals,Northwest,Ethiopia,2021(n=385) cont... 
Insulin regimen

Lent\& regular ${ }^{\circledR}$

NPH\& regular

$0.840(0.631-1.118)^{\star}$

0.757(.538-1.066)

0.111

$\mathrm{NPH}$ alone

$0.704(0.511-0.970)^{*}$

1.305(0.856-1.990)

0.216

Carbohydrate counting

NOß

Yes

$4.173(2.332-7.468)$ *

2.433(1.124-5.263)

$0.024^{\star *}$

Frequency of glycemic control per day

$<3 \circledR$

$>=3$

$1.904(1.409-2.574)$ *

$1.259(0.887-1.788)$

0.198

Physical exercise

$\mathrm{NO} \circledast$

$\begin{array}{llll}\text { Yes } & 2.574(1.991-3.326)^{*} & 1.178(0.841-1.649) & 0.341\end{array}$

Noncompliance behavior assessed by clinician at health care visit

$\mathrm{NO} \circledast$

$\begin{array}{llll}\text { Yes } & 0.334(0.248-0.451)^{\star} & 1.222(.805-1.853) & 0.346\end{array}$

Adherence to diabetic care

$\mathrm{NO} B$

Yes

$6.522(4.901-8.679)$ *

9.723(6.094-15.513)

$<0.001^{* *}$

Duration of DM in years

$<2 ®$

[2-4)

$0.559(0.401-0.781)$

0.736(0.509-1.063)

0.102

$>=4$

$0.486(0.356-0.664)^{*}$

$0.642(0.436-0.944)$

$0.024^{\star \star}$

Diabetes related acute complication

$\mathrm{NO} \circledast$

Yes

$1.591(1.031-2.457) * \quad 1.084(.653-1.799)$

0.755

Other complication

$\mathrm{NO} \circledast$

Yes

$0.746(0.456-1.221)$

History of comorbidity

NO尺

Yes

$0.627(0.484-0.811)^{\star}$

$0.722(0.530-0.981)$

$0.038^{\star \star *}$

CHR $=$ Crud hazard ratio, AHR=Adjusted hazard ratio, $R x=$ Treatment, $\Theta=$ Reference group and $* \& *$ indicates statistically significant variable with bivariable\& multivariable cox regression hazard model respectively.

\section{Figures}




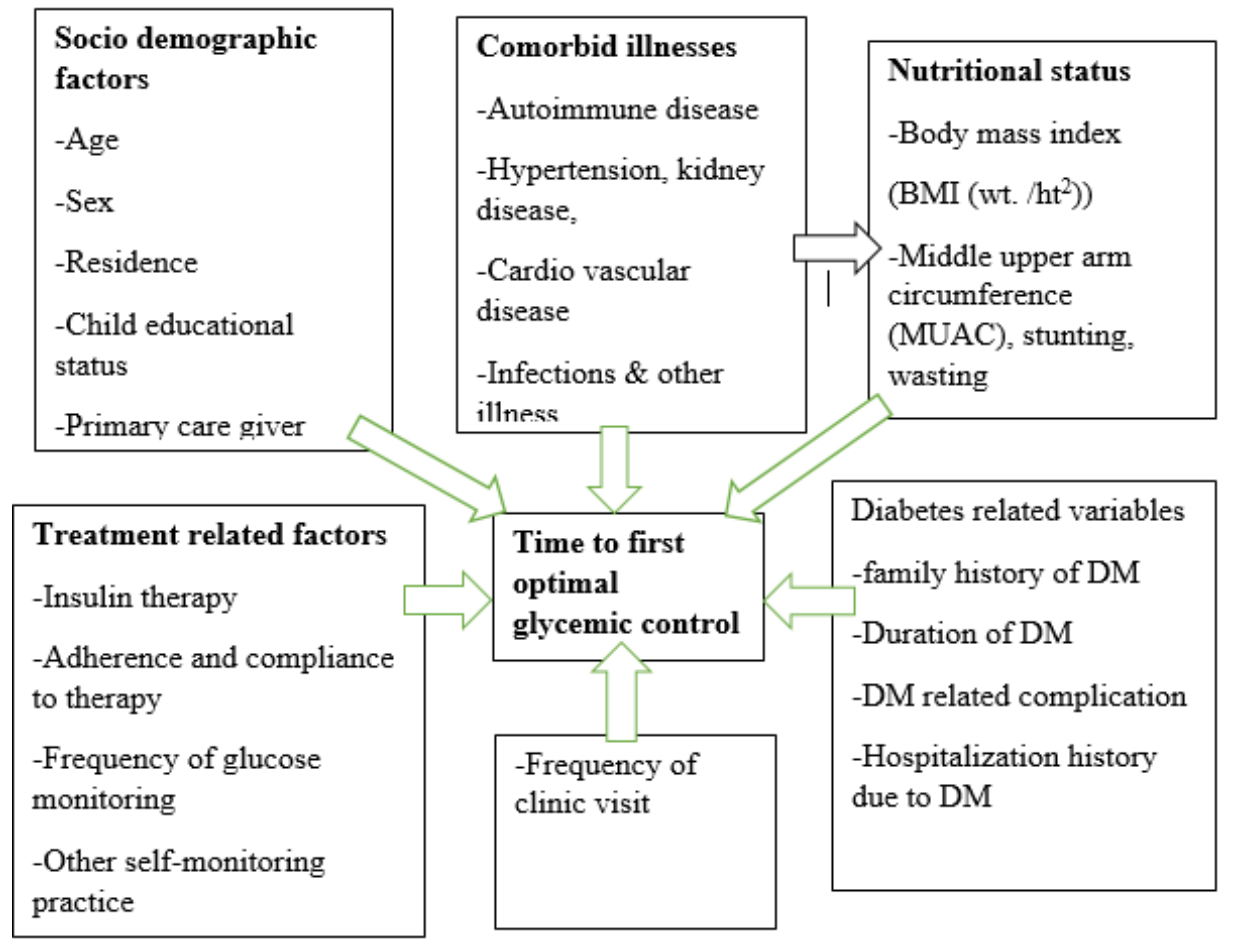

\section{Figure 1}

Time to glycemic control concept map among type 1 diabetic children in Bahir Dar city public referral hospitals,Northwest,Ethiopia,2021; adapted from $(, 36,40,50,79)$ 


\section{Kaplan-Meier survival estimate}

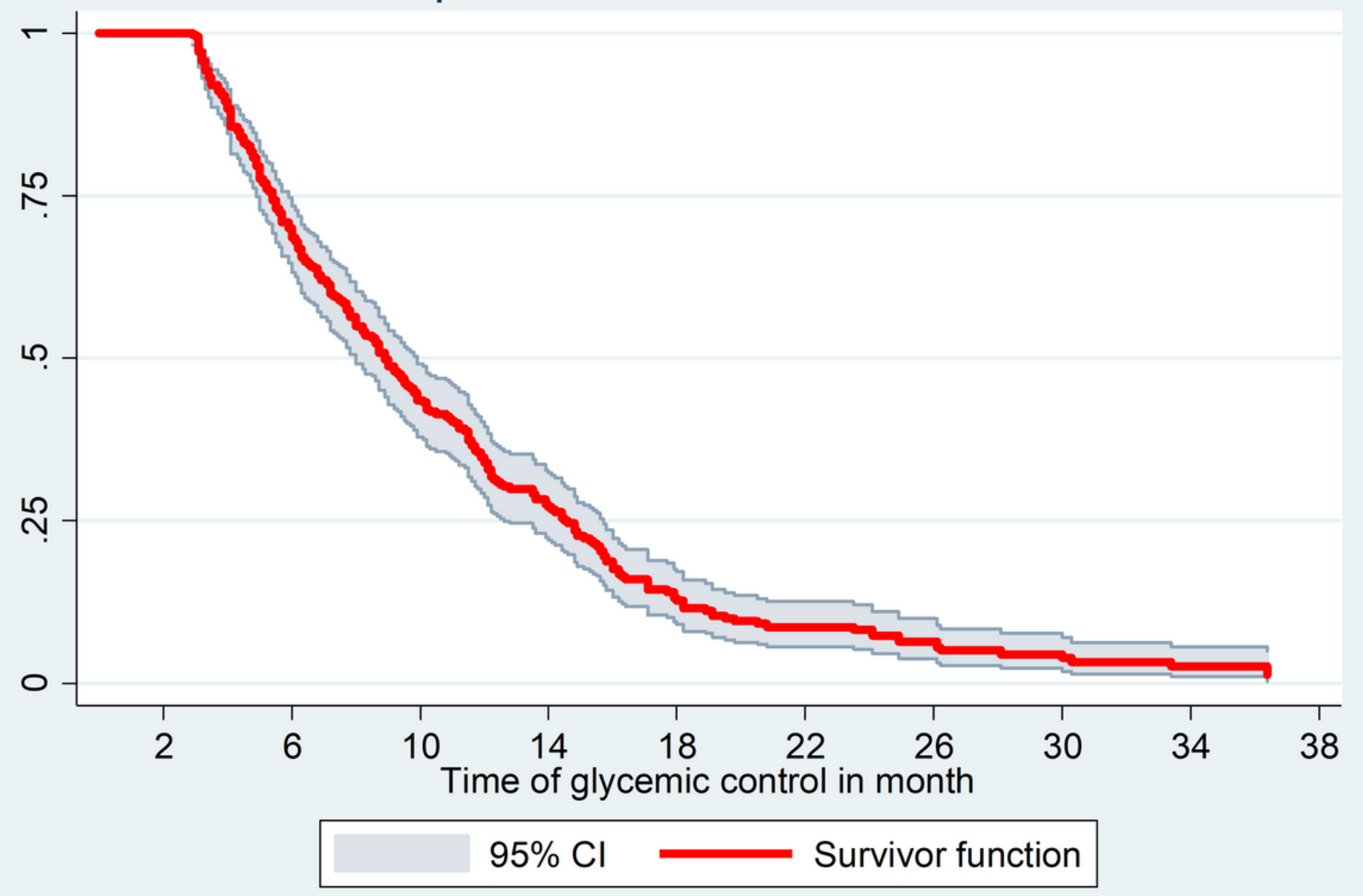

Figure 2

Kaplan-Meier survival estimate of time to first optimal glycemic control among type 1 diabetic children having follow up at Bahir Dar city public referral hospitals, 2021 


\section{Kaplan-Meier survival estimates}

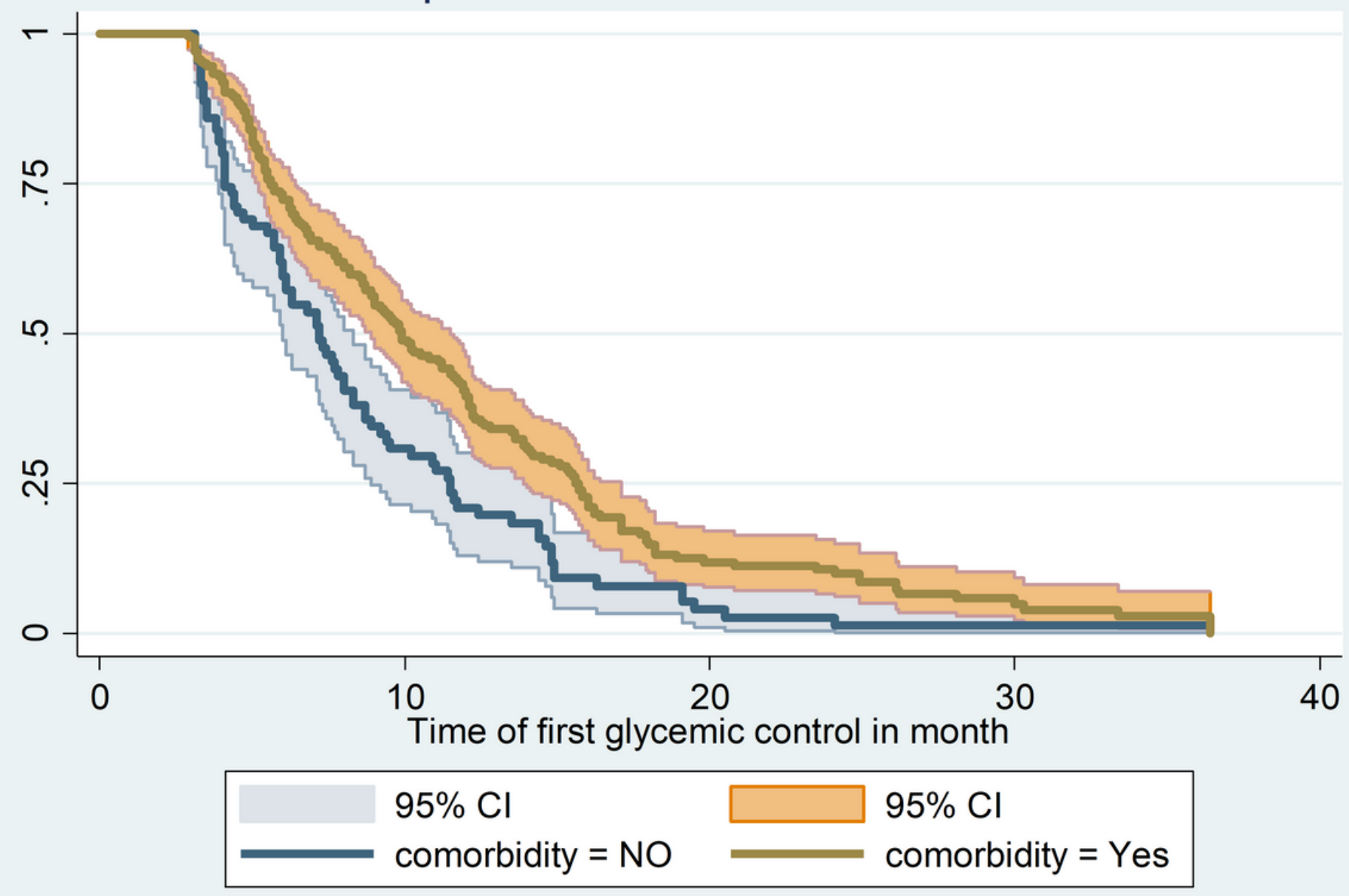

Figure 3

Kaplan Meier survival estimate for time to optimal glycemic control among type 1 diabetic children with history of comorbidity in Bahir Dar city public referral hospitals, Northwest, Ethiopia, 2021 

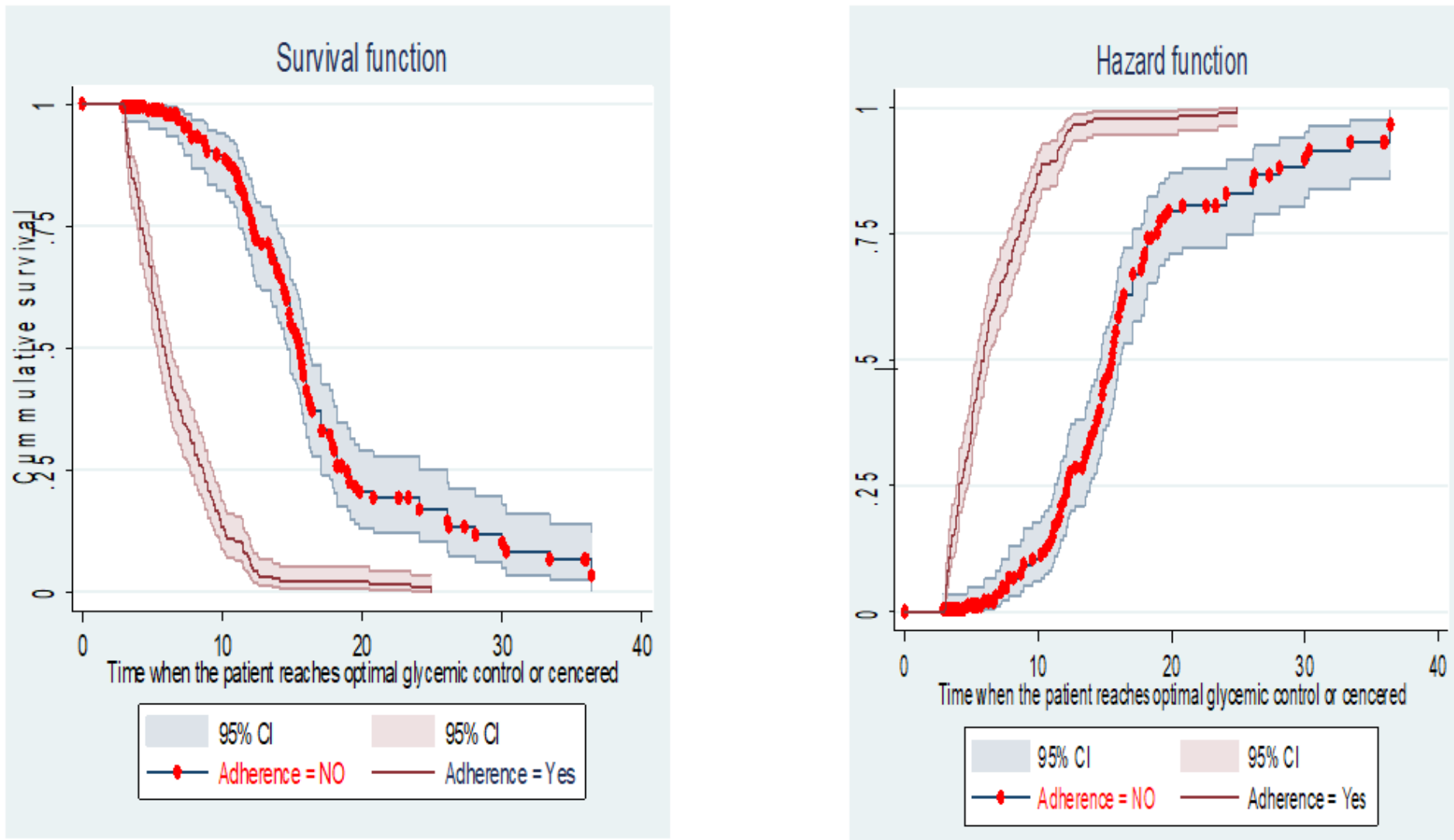

\section{Figure 4}

survival and hazard function of adherence by time (in month), Bahir Dar city public referral hospitals, Northwest, Ethiopia, 2021 


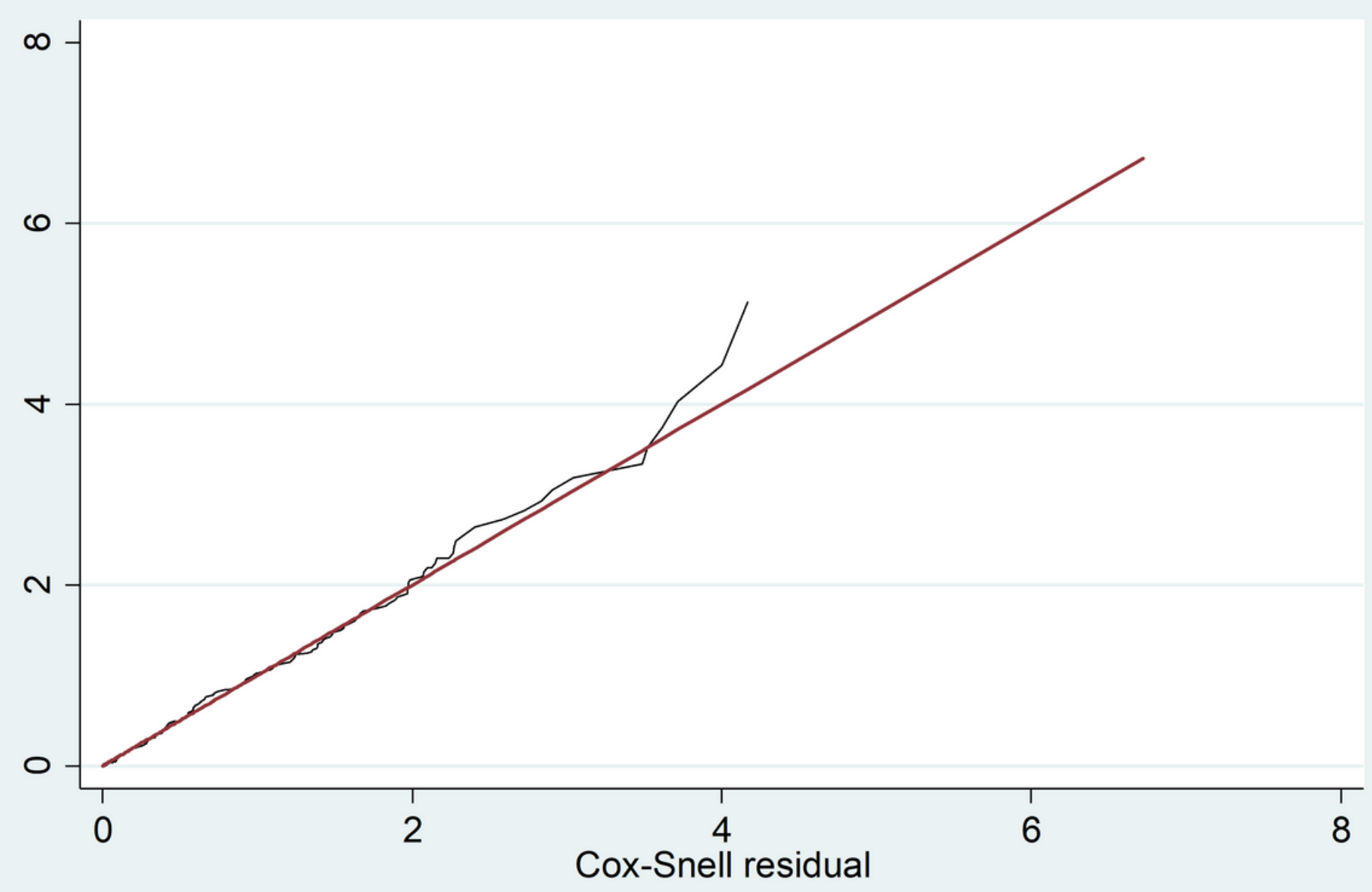

\section{$\mathrm{H} \longrightarrow$ Cox-Snell residual}

\section{Figure 5}

Model goodness of fit by cox Snell residual among type 1 DM clients, Bahir Dar city public referral hospitals, Northwest, Ethiopia, $2021(n=385)$
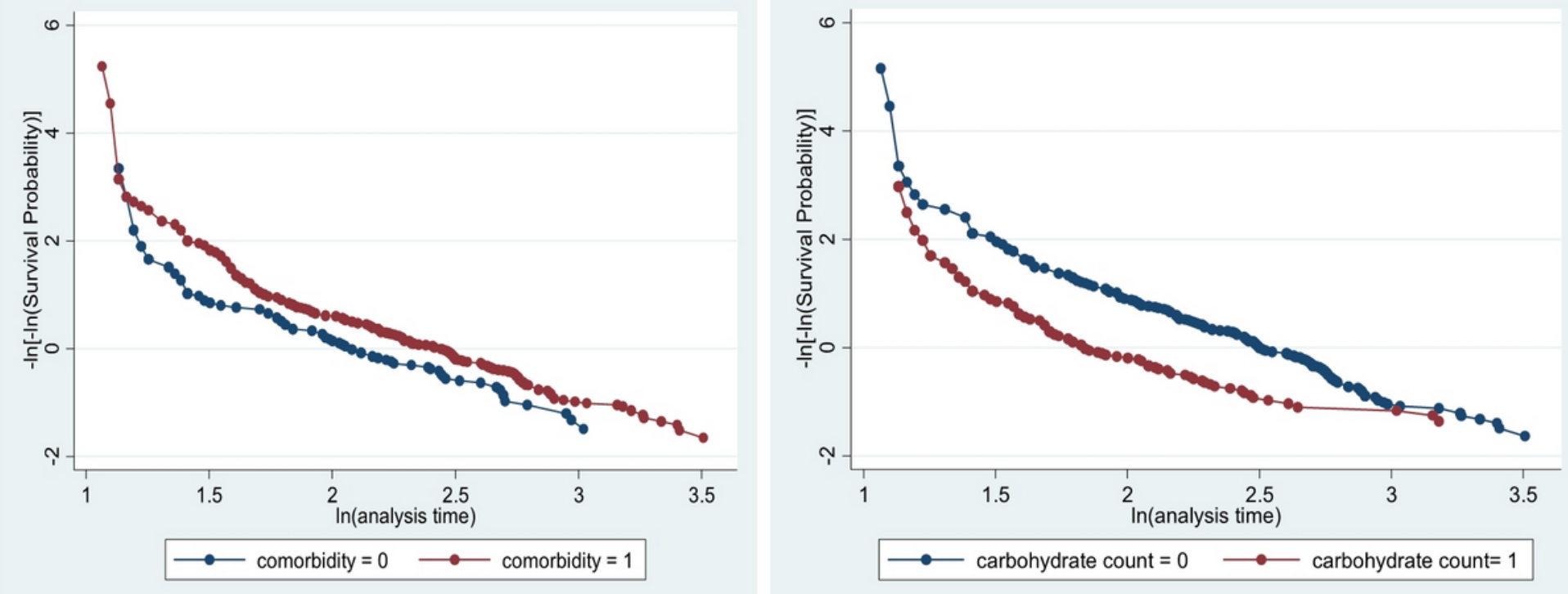

Figure 6 
log of minus the Log of survival function by comorbidity and carbohydrate count for time to first optimal glycemic control among type 1 diabetic children, Bahir Dar, 2021 